Sussmann are, but they have been ignored. Zahler and Sussmann have discovered that "catastrophe theory is a blind alley" because they have blinded themselves to anything hopeful that they might see. Surely a review of the "accomplishments of applied catastrophe theory" should not be so narrow. In particular, it should at least mention the work of J. M. T. Thompson on elastic stability (Nature 254, 392-395 (1975)).

Zahler and Sussmann are also snide. They denigrate catastrophe theory for the "large number of (mostly unrefereed) publications praising each other extravagantly". This is an attempt at character assassination due to the fact that many papers are published in conference proceedings. I

\section{Censuring repressive regimes}

SIR,-Every four years the International Union Against Cancer organises a huge international cancer congress, typically attended by perhaps 6,000 scientists. The next one is scheduled for 5-12 October 1978 in Buenos Aires, Argentina. However, in Science (21 October) and Nature (3 November, page 8 ) groups of scientists, including two recent Nobel prizewinners for medicine, have called on other scientists to boycott this conference because, it is claimed, "scientists, physicians, professors, journalists, intellectuals, and other (Argentinian) citizens have been arrested, imprisoned without benefit of habeas corpus, often tortured and sometimes executed without trial". These allegations are supported by editorials in Nature (263, 452; 1976 and 266, 395; 1977).

We were telephoned by the press for comment on these letters, but could not comment because, like many other full time scientists, we were necessarily ignorant of conditions in most foreign countries. We therefore made contact with Amnesty International (AI), in the hope of securing some reasonably unbiased data. The 'Report of the AI Mission to Argentina' (1977) and the detailed letter which the Director of AI sent us appear to be objective and impartial, and the conditions they describe are really appalling.

Briefly, there was a military coup in March 1976. During the next six months about 2,000 Argentinians were killed by the government or (almost equivalently, it seems) disappeared. Killings and disappearances of nonviolent Argentinians (a priest, for example, who said a requiem mass for a parishioner who had been killed by government agents) continue at a rate think the remark is out of place-indeed I think the whole paper is out of place. It is deceptive, and it is not what is purports to be. There is much to be criticised in work which has been done using mathematical models based upon catastrophe theory, but the criticism of Zahler and Sussmann is merely mean spirited.

\section{JOHN GUCKENHEIMER}

University of California, Santa Cruz SIR,--My paper, to which Zahler and Sussmann refer, was presented as a discussion paper at a meeting of the New York Academy of Sciences. It was directed to a general audience at a time when catastrophe theory was not widely known. Since I could not presume a detailed knowledge of the theory or of biology, I intended to give

of hundreds a month, and frequently bodies are discovered, some of people recently arrested, many with evidence of severe torture. Recent Argentinian laws explicitly forbid newspapers to report, comment on or make reference to abductions or the discovery of bodies, and also forbid propagation through any medium whatever of news or views with the purpose of lessening the prestige of the armed forces!

In the apparently impartial opinion of the Director of AI (personal communication, 25 October), "the state of affairs in Argentina is now one of the most serious in the world: Argentina has probably, since March 1976, the largest number of prisoners of conscience, disappearances and political killings in the whole of Latin America". (In most cases, according to AI, those affected were not terrorists.) However, even if, among many bad countries, Argentina is worst in this respect, it does not follow that a boycott is wise, for it is difficult to estimate the true probabilities of all its possible effects (especially if one is distracted by suppositions about the motives of the scientists who propose it or of those who oppose it).

It must be recognised by the proponents of any boycott that it is very unlikely to have much impact on the repression of non-violent citizens, while the opponents of a boycott must equally concede that there does exist a small probability that it would materially accelerate humanitarian progress. Balancing these considerations are the medical advantages of holding a cancer congress, but here a rather curious analogy exists; one single congress is very unlikely to have much impact on human cancer, but there does exist a small probability that it will materially accelerate medical progress. Moreover, because the Argentinian junta are apparently (Financial Times, 14 September) having difficulty, simplified explanations of both so that I might suggest possible uses of the theory in biology.

May I also suggest that one illustration of a catastrophic jump might be the apparent discontinuity in Sussmann's opinion of Zeeman's paper (in Towards a Theoretical Biology 4 (1972)). In 1975 Sussmann (Synthese 31, 229 (1975)) writes "in most applications what is used is not catastrophe theory as a set of results, but catastrophe theory as a conceptual framework (for an example, see Zeeman's beautiful paper in Towards a Theoretical Biology on heartbeat and nerve impulse)". Now, writing with Zahler he expresses a very different opinion.

A. E. R. WoodCock

Williams College, Massachusetts, USA

because of their human rights record, in securing foreign investment and arms, it is uncertain which probability is smaller in this particular balance.

One must also ask, however, if scientific meetings are boycotted, where it will all end. In a related academic field, for example, the International Epidemiological Association will meet in Iran in 1979 and, overall, a large number of international scientific meetings take place in countries with governments which kill, or torture, or imprison non-violent citizens. If these several meetings were all avoided, so many different governments would thus be censured that none would thereby be singled out for special attention, and the net effect might merely be to forfeit the rather useful apolitical image which science has earned, while achieving little or no humanitarian progress. It might be practicable just to boycott those governments which persecute many scientists, but this seems rather artificial, and might merely aggravate anti-science sentiments. Moreover, the scientists who live in some of the countries concerned might much rather have a week or two of contact with the international community than suffer continued intellectual isolation. Perhaps, anomalously, boycotts do more harm than good in states with closed frontiers (unless the state would also restrict free attendance), but perhaps they are occasionally useful in states with open frontiers.

Advice and comments from other scientists, especially those who, unlike ourselves have actually worked under repressive regimes, would be timely, both about the general advisability or inadvisability of such boycotts (ignoring everybody's motives, please), and also about the specific 12th Cancer Congress in Argentina next year.

Richard PETO RICHARD DOLL

University of Oxford, $U K$ 